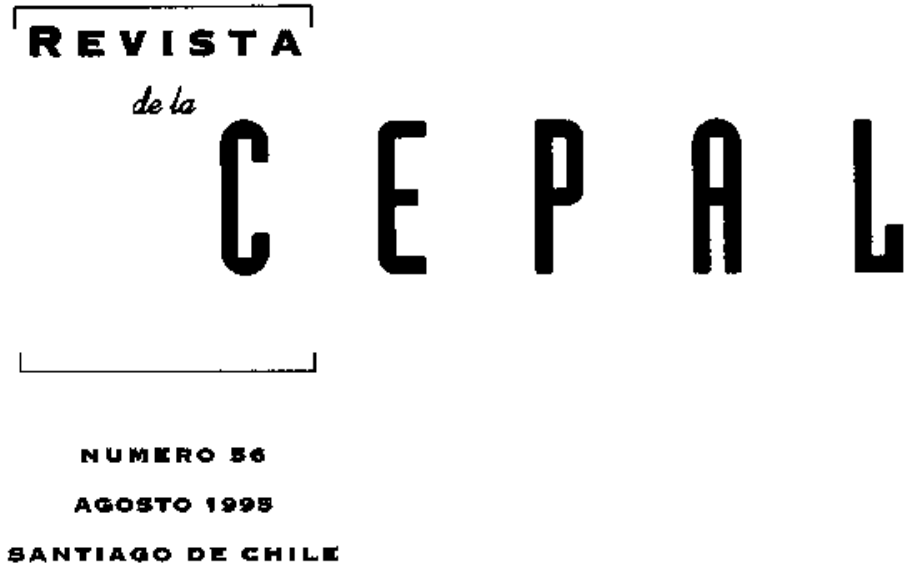

ANIBAL PINTO

Director

EUGENIO LAHERA

Secretario Técnico

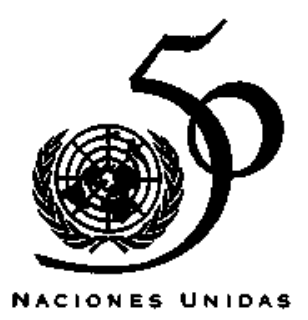


Democracla y desarrollo

Fernando H. Cardoso

¿Es posible crecer con equidad?

Joseph Ramos

Estabilidad y estructura: Interacclones en el crecimiento económlco

Jose Maria Fanelli y Roberto Frenkel

Reforma a los sistemas de pensiones en América Latina

Andras Uthoff

Tendenclas económicas en China: significado para el comerclo con América Latina y el Caribe

Mikio Kuwayama

El Intercamblo económico entre América Latina y las

economias dinámicas de Asla

Ronald Sprout

La relación económica entre la Amórica Latina y la Unlón Europea

Roberto Smith Perera

Nuevas implicaclones de las reglas do orlgen

Eduardo Gitli

Globalización y reestructuración energética en Amórlca Latina

Fernando Sánchez Albavera

El caloidoscoplo de la competitlvidad

Geraldo Muller

La privatización de los servicios públicos del agua

Miguel Solanes

¿Cuénto se puede gastar en educaclón?

Guillermo Labarca

Mujeres y migranteo: deslgualdades en el

mercado laboral de Santlago de Chile

Ivonne Szasz

Orlentaciones para los colaboradores de la Rovista de la CEPAL 


\section{¿Es posible crecer con equidad?}

\section{Joseph Ramos}

Director,

División de Desarrollo

Productivo y Empresarial. CEPAL
El artículo presenta el tema en el contexto del debate terrico y empírico, iniciado por Kuznets, respecto a la posibilidad de lograr un crecimiento con equidad. Concluye que no hay un conflicto ineludible entre estas dos metas, siempre que la politica economica potencie las áreas de complementariedad entre crecimiento y equidad. Rechaza los enfoques que presuponen un conflicto insuperable entre ambas metas: tanto la teoría del "chorreo"(que acepta el conflicto con estoicismo, y propone esperar todo el tiempo que se requiera) como el enfoque "paralelo" (que está dispuesto a sacrificar el crecimiento en pos de la equidad, asignándole a la política social el papel de corregir los peores efectos distributivos de la politica económica). Aboga por un enfoque "integrado", en que la política económica incorpore consideraciones distributivas y la social consideraciones de eficiencia, y ambas potencien las áreas de complementariedad entre crecimiento y equidad. Sefíala cuatro areas de complementariedad importante entre ambas metas, tres bastante consensuales (la mantención de los equilibrios macroeconómicos dentro de márgenes tolerables; la inversión en recursos humanos; una política de pleno empleo productivo); y una menos consensual, pero que apoya la CEPAL: la rápida y masiva difusión tecnologica. Por último, el artículo señala las diferencias instrumentales entre los enfoques de la CEPAL y del neoliberalismo en siete áreas concretas de política económica. El enfoque neoliberal privilegia la desregulación y liberalización de los mercados, la neutralidad de los instrumentos y cierta pasividad del Estado. El enfoque de la CEPAL, en cambio, propone acciones selectivas por parte del Estado para llenar los vacíos y fallas más importantes en los mercados de factores. Sin ello, es improbable que la región pueda alcanzar los elevados ritmos de crecimiento económico que la historia muestra que son posibles para países de desarrollo tardío, ni ciertamente que lo haga con equidad. 


\section{I}

\section{Introducción}

Después de casi una década de estancamiento económico y rezago social, la mayoría de los parses de América Latina y el Caribe han procurado con ahinco estabilizar y reestructurar sus economías, y han logrado detener la inflación galopante, liberalizar los mercados, reducir la protección excesiva y redefinir los roles del sector público y del privado, reconociendo el papel fundamental de este último en la producción.

Tales reformas, sin embargo, han tenido su costo, y lo que es más grave aún, en la mayoría de los casos éste no se ha compartido equitativamente. El éxito de las reformas dista de estar asegurado, (como lo demuestra, sin ir más allá, la crisis mexicana de 1994-1995) y la propia democracia puede ponerse en riesgo porque muchos de los avances se han logrado a expensas de la población más pobre. Vemos así que el crecimiento con equidad no sólo es imperioso desde el punto de vista ético, sino que también es indispensable desde un punto de vista político. Pero esto plantea una gran interrogante: ¿es técnicamente posible crecer con equidad?

De hecho, en la literatura económica, al menos desde Kuznets, se suele considerar que estos objetivos se contraponen, por lo cual algunos postulan un enfoque secuencial: primero se crece y posteriormente viene la eventual redistribución. Como se ha visto que este efecto tarda demasiado, otros optan por sacrificar algo de crecimiento en pos de una mejor distribución de sus frutos, y asignan a la política social el papel de compensar o corregir los efectos regresivos de algunas políticas económicas. El problema que plantea este segundo enfoque es que esos efectos regresivos son de tal magnitud que ninguna política social realista podría compensarlos.

Afortunadamente, el análisis de las experiencias en la posguerra de muchos países en desarrollo -en especial, pero no exclusivamente, de algunos países

D Este artículo se basa en la obra Equidad y transformación productiva: tun enfoque integrado (CEPAL, 1992), cuya redacción este autor coordino. asiáticos de industrialización reciente- ${ }^{1}$ muestra que el conflicto entre crecimiento y equidad es evitable. Hay importantes áreas de complementariedad, y no sólo de conflicto, entre los objetivos de crecimiento y equidad. La primacía de las primeras depende de las políticas que se apliquen. En efecto, es posible crecer y mejorar la equidad en forma simultánea y no secuencial siempre que se aplique un enfoque integrado que incorpore en la política económica tanto el objetivo de equidad como el de crecimiento, y que la política social otorgue prioridad no sólo a la equidad, sino también a la eficiencia. En tal caso, las políticas económicas y sociales deben centrarse en potenciar los aspectos complementarios entre crecimiento y equidad, y en minimizar los de posible conflicto.

Por cierto, si bien el crecimiento con equidad es posible, no es ni fácil ni automático. Por mucho consenso que haya hoy sobre la importancia para el desarrollo de la economía de mercado y de un sector privado pujante -consenso que comparte la CEPALes preciso reconocer que éstas son condiciones necesarias pero no suficientes del crecimiento, y menos aún del crecimiento con equidad. Si lo fuera, el ingreso per cápita de la región no equivaldría a un quinto $o$ un décimo del de los países desarrollados, ni el $40 \%$ de su población viviría en la pobreza como lo hace hoy, ya que por lo menos durante los primeros 120 de los 180 años de vida independiente de la región (y durante casi 450 de los 500 años transcurridos desde su colonización), su economía se organizo en torno a la propiedad privada, al sistema de mercado, y a un Estado pequeño y pasivo. Esto nos indica que el crecimiento con equidad exige no sólo una economía de mercado, sino también una vigorosa acción pública para aprovechar al máximo las posibilidades de complementación en pos de ambos objetivos.

1 VEase por ejemplo Fields, 1991. Al analizar 70 casos de procesos de crecimiento en países en desarrollo en la posguerra, se vio que en la mitad de ellos el crecimiento se dio paralelamente con un deterioro de la distribución del ingreso, lo que coincide con la hipotesis de Kuznets; pero en los demás casos, la distribución del ingreso mejoro o al menos se mantuvo invariable. Por lo tanto, estos dos objetivos no se excluyen mutuamente, como postulan las teorías tradicionales. 


\section{II}

\section{Areas de complementariedad}

Ha comenzado a emerger un consenso en que las principales areas de complementariedad entre crecimiento y equidad son la mantención de los equilibrios macroeconómicos, en primer término, y en seguida la inversión en recursos humanos, la generación de empleo productivo y la modernización tecnológica.

\section{Mantenclón de los equllibrios macroeconómlcos básicos}

La experiencia demuestra que las peores contracciones de los ingresos en términos absolutos, así como sus mayores retrocesos, se han debido tanto a recesiones producidas por ajustes ante déficit insostenibles en cuenta corriente (acompañados por fuertes devaluaciones y caídas en el producto y los salarios reales, como sucedí en la crisis de la deuda en 1982-1983 y la crisis mexicana en 1994-1995); y a recesiones causadas por inflaciones desatadas en las que los salarios reales han caído hasta un 50\%, como sucedió en Argentina (19881990), Brasil (1990-1991), Bolivia (1982-1984), Nicaragua (1987-1990) y Perú (1988-1989), o a posteriores intentos de estabilización mal diseñados o implementados, como en Chile (1974-1975), Perú (1990-1992) y Venezuela (1989). En efecto, en los casos de inflación desatada los salarios suelen ir a la zaga de los precios, porque las clases humildes tienen menos mecanismos de defensa contra la inflación galopante. Por otra parte, si los posteriores programas de estabilización redundan en una baja de la producción, ya sea porque están mal concebidos o por falta de credibilidad, el nivel de empleo se reduce, a raíz de lo cual bajan tanto los salarios como la participación de los trabajadores en el ingreso nacional. Por lo tanto, las medidas destinadas a evitar tales desequilibrios favorecen a la vez el crecimiento y la equidad.

\section{Inversión en recursos humanos}

La inversión en recursos humanos es necesaria para romper el círculo vicioso de la pobreza. Entre otras cosas, permite reducir la tasa de fecundidad de las mujeres pobres, cuyos hijos corren mayor riesgo de ser desnutridos, tienen menores posibilidades de aprovechar la educación que reciben, y como ésta tiende a ser deficiente, suelen terminar realizando trabajos con muy baja productividad, perpetuándose así el círculo vicioso de la pobreza. Para evitar que esto ocurra hay que adoptar medidas que tiendan a reducir la fecundidad efectiva a los niveles deseados por los cónyuges y a los hijos que ellos puedan mantener responsablemente; a eliminar la desnutrición mediante programas de salud maternoinfantil; a continuar ampliando la cobertura del sistema educacional, objetivo que se ha logrado en buena parte de la región, y sobre todo a elevar la calidad de la educación y adecuarla en mayor medida a las necesidades de recursos humanos.

\section{Generación de empleo productivo}

El desempleo o el trabajo marginalmente productivo (subempleo) no es sólo un problema social, sino también una señal de gran ineficiencia económica, pues supone desaprovechar el potencial productivo de gran parte de los recursos humanos de un país. Además de afectar a los cesantes, el desempleo influye negativamente en los salarios, por lo que también afecta a quienes están empleados. El alto nivel de desempleo y subempleo explica el marcado deterioro de los salarios reales en la región durante los años ochenta, cuya caída en general fue más acentuada que la del producto per cápita y de la productividad. No es sorprendente, entonces, que los frutos del progreso no alcancen a las grandes mayorías y que se concentren en las manos de unos pocos.

Por tal motivo, la CEPAL considera que el logro del pleno empleo es un excelente ejemplo de la posibilidad de crecer con equidad. Pero no se trata de cualquier tipo de pleno empleo, sino de empleo cabalmente productivo. En efecto, si bastara cualquier trabajo para asegurar el pleno empleo hasta el año 2000 , se podría simplemente prohibir el transporte de carga en vehículos; pero el empleo resultante, como es obvio, no sería cabalmente productivo. No basta, por lo tanto, con aplicar políticas de emergencia que generen empleo transitorio 0 de escasa productividad, sino que también es necesario estructurar la política económica en general en tomo a la generación de empleo productivo con medidas específicas como las mecionadas más adelante (especialmente en el apartado 2, acápites a, b y c de la sección III). 


\section{Modernización tecnológica}

La CEPAL postula que el mejoramiento de la competitividad internacional debe basarse en un constante aumento de la productividad por medio de la modernización tecnológica. Por lo tanto, rechaza la competitividad basada en salarios bajos o el deterioro del medio ambiente y que arroja beneficios una sola vez, por considerarla seudocompetitividad o competitividad espuria. Un ejemplo clásico es el del imperio español, que pese a su acceso a las riquezas naturales del nuevo mundo, quedó muy a la zaga del imperio británico, cuyo progreso se basó en un avance tecnológico sistemático.

A nuestro juicio, la existencia de un porcentaje tan alto de pobres en la región ( $40 \%$ ) se debe en gran medida a que son muchos los trabajadores que laboran en empresas con equipos insuficientes y anticuados, por lo que su productividad es muy limitada y sus salarios muy bajos. Esta situación perdurará mientras la productividad de la empresa típica de la región siga siendo un tercio o la mitad de la productividad de la empresa típica de los países desartollados, incluso si se toman en cuenta las diferencias en la escasez relativa de los factores. La generación de empleos cabalmente productivos implica, pues, una aceleración del proceso de difusión tecnológica.

A primera vista se podría pensar que hay un conflicto entre el avance tecnológico y el empleo, pero éste es sólo aparente. Hay muchos adelantos técnicos que permiten ahorrar mano de obra y que junto con reducir el empleo de baja productividad elevan el de alta productividad. Además, los avances tecnológicos más importantes no sólo disminuyen la demanda de mano de obra poco calificada, sino que por lo general también permiten ahorrar capital, que es el factor más escaso. Por ejemplo, las actuales calculadoras de bolsillo, que valen diez dólares, efectúan las mismas operaciones que las calculadoras electromecánicas de $\mathbf{2 0}$ años atrás, cuyo costo excedía los 200 dólares, y las hacen en mucho menos tiempo. El ahorro de capital que esto supone permite generar empleo productivo en éste y otros rubros. Ejemplos similares abundan no sólo en la informática, sino también en las comunicaciones, el transporte aéreo y marítimo, la electrónica, la biotecnología, el desarrollo de muevos materiales y otras actividades.

Dado que el avance tecnologico puede tener variados efectos, hay que dar prioridad a la rápida difusión tecnologica, especialmente en sectores rezagados que hacen uso intensivo de mano de obra. En efecto, cuanto más lenta sea la difusión tecnológica, menores serán el crecimiento del producto y la generación de empleos de alta productividad, pues la gran mayoría de las empresas continuará operando con tecnología obsoleta. En cambio, cuando se acelera el proceso de difusión tecnológica aumentan tanto el producto como los empleos de alta productividad (gráfico 1).

ORAFICO 1

Efectos del ritmo de la difusion tecnológlca en el crecimiento, el empieo y la
dlstrlbución del ingreso

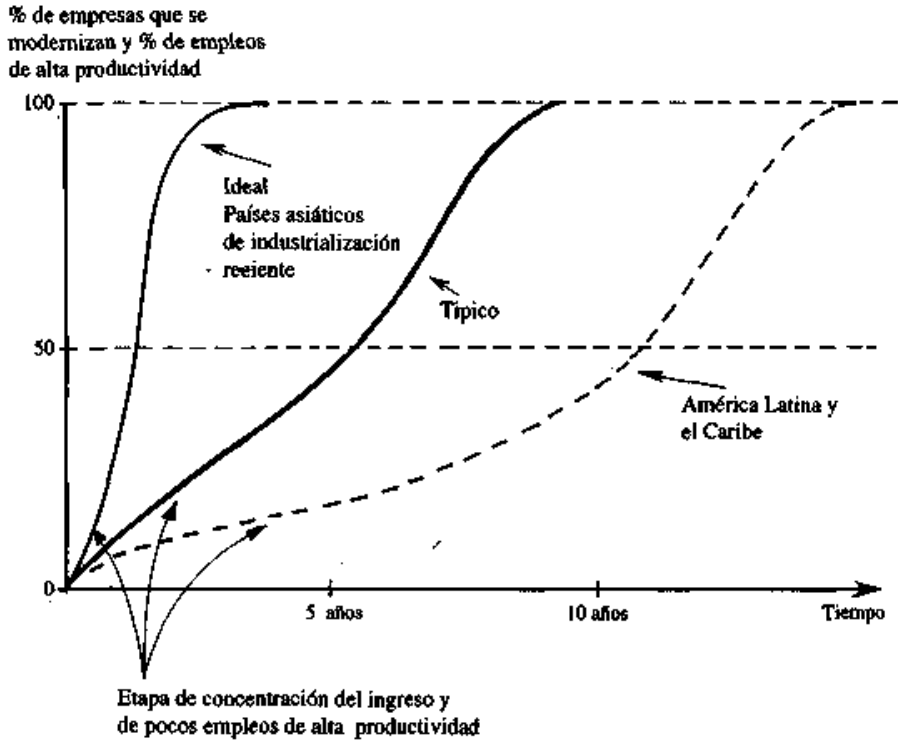

Fuente: Elaboración propia. 
III

\section{Areas de discrepancia}

Aunque hay un creciente consenso en que el crecimiento con equidad exige la mantención de los equilibrios macroeconómicos basicos y una estrategia orientada a elevar la competitividad internacional por medio de la modernización tecnológica, la generación de pleno empleo productivo y la inversión en recursos humanos, existen sin embargo importantes discrepancias en lo que toca a enfoques y a instrumentos.

\section{Discrepancias en cuanto a entoques}

Ya hemos dicho que la CEPAL rechaza la tesis del "goteo" o "derrame", porque la experiencia histórica demuestra que el crecimiento no conduce automaticamente a la equidad, al menos no en un plazo razonable sino al cabo de muchas décadas. Tampoco concuerda con el enfoque que impone a la política social un objetivo prácticamente inalcanzable: el de compensar los efectos regresivos de numerosas políticas económicas. La CEPAL aboga por un enfoque integrado en virtud del cual se incorporen consideraciones de equidad a la política económica y de eficiencia a la política social; de acuerdo con dicho enfoque es preferible, por ejemplo, evitar la cesantía mediante una política macroeconómica y de crecimiento orientada a la estabilización de los precios y al logro del pleno empleo, que otorgar subsidios de desempleo.

\section{Discrepanclas en cuanto $a$ instrumentos}

Algunos autores, por lo general neoliberales, abogan por desregular y flexibilizar los mercados y por un papel más bien pasivo para el Estado. La CEPAL, en cambio, postula que también se necesitan acciones públicas vigorosas, aunque selectivas, para superar los estrangulamientos más críticos y así evitar que el crecimiento sea lento y concentrador (véase de nuevo el gráfico I).

En casi todas las teorías ortodoxas se privilegia la liberalización de los precios y la flexibilización y desregulación de los mercados. Según estas teorías, el subdesarrollo se debe esencialmente a la intervención gubernamental en los mercados y su postulado implícito es que el precio que rige en un mercado desregulado es necesariamente el precio "correcto" o de equilibrio. En cambio, según el enfoque neoestructural que aplica la CEPAL, varios mercados claves tienen fallas críticas por las cuales el precio que equilibra la oferta y la demanda en un momento dado puede no ser el precio de equilibrio de largo plazo, es decir, el que refleja la escasez real de bienes y, sobre todo, de factores. A continuación se muestran las diferencias entre el enfoque neoliberal y el neoestructural de la CEPAL en lo que toca a los instrumentos que se pueden utilizar para fortalecer las áreas de complementariedad (véase también el cuadro 1).

\section{a) Incremento del ahorro público o reducción del deficit}

Todos los expertos concuerdan en que el incremento del ahorro público, o la reducción del déficit, son condiciones necesarias para mantener los equilibrios macroeconómicos dentro de márgenes tolerables. Para que el déficit disminuya hay que reducir el gasto público o elevar la recaudación. Si bien desde el punto de vista macroeconómico da lo mismo por qué vía se logra eliminar el déficit, ${ }^{2}$ no da lo mismo desde el ángulo del crecimiento y la equidad. En efecto, la reducción del gasto - que fue la prédica ortodoxa así como la práctica típica de la región en los años ochenta- dificulta aún más el cumplimiento de las funciones básicas del sector público en lo que se refiere a inversion en infraestructura y en recursos humanos, ambas indispensables para un crecimiento con equidad.

En vista de lo anterior, la CEPAL propone revertir la preferencia por la reducción del gasto y hacer hincapié en el incremento de la recaudación tributaria.

Más aún, en la medida en que la inflación es un impuesto (implícito, por cierto, pero no por eso menos real), el aumento de la recaudación tributaria para

\footnotetext{
2 En rigor, incluso desde el punto de vista macroeconómico no da lo mismo como se logra el equilibrio. Por un lado no sólo se necesita equilibrar las cuentas fiscales (o generar superavit), sino que el equilibrio debe ser crefble para que se consolide la estabilidad. De ahí que debe lograrse con un nivel de gasto considerado factible de mantener a largo plazo y no con uno transitoriamente comprimido. Por otra parte, el nivel de ahorro también debe ser considerado estable, lo que implica un alto nivel de ahorro nacional y no sólo externo para evitar una alta vulnerabilidad interma (piénsese de nuevo en la crisis mexicana de 1994-1995 y en la alta vulnerabilidad argentipa actual).
} 
CUADRO 1

EQUIDAD Y CRECIMIENTO: PROPUESTA OATODOXA Y PROPUESTA DE LA CEPAL

\begin{tabular}{|c|c|c|c|c|}
\hline \multirow[t]{2}{*}{ Objetivos } & \multicolumn{2}{|c|}{ Propuesta ortodoxa } & \multicolumn{2}{|c|}{ Propuesta de lacEPAL } \\
\hline & Pollticas & Problemas derivados & Polfticas & Instrumentos \\
\hline 1. Ahorto público & $\begin{array}{l}\text { Reducir el gasto. } \\
\text { Focalizarlo (hacer gastos } \\
\text { más "progresivos") }\end{array}$ & $\begin{array}{l}\text { Nivel de recaudación } \\
\text { insuficiente para la } \\
\text { inversion en } \\
\text { infraestructura y capital } \\
\text { humanos Asimetria entre } \\
\text { ajuste de gastos } \\
\text { e ingresos. }\end{array}$ & $\begin{array}{l}\text { Hay margen para elevar } \\
\text { la carga tributaria } \\
\text { (ingresos directos). } \\
\text { Hacer más progresiva la } \\
\text { recaudación. }\end{array}$ & $\begin{array}{l}\text { Ampliación de la base } \\
\text { de tributación. } \\
\text { Reducción de la evasión } \\
\text { tributaria. } \\
\text { Algunas exenciones } \\
\text { al iva. } \\
\text { Gravarnen de automóviles, } \\
\text { propiedades y combustibles. }\end{array}$ \\
\hline 2. Ahorro privado & $\begin{array}{l}\text { Elevar la tasa de interés. } \\
\text { Comprimir los salarios. }\end{array}$ & $\begin{array}{l}\text { Impacto insuficiente. } \\
\text { Redistribución del } \\
\text { ingreso hacia ahorrantes } \\
\text { tradicionales (ricos). }\end{array}$ & $\begin{array}{l}\text { Elevar el ahorro de los } \\
\text { asalariados por medio de } \\
\text { cambios institucionales. }\end{array}$ & $\begin{array}{l}\text { Ahorro para la vivienda. } \\
\text { Ahorro forzoso, cerrando } \\
\text { el déficit actuarial y de } \\
\text { caja del sistema previsional. }\end{array}$ \\
\hline $\begin{array}{l}\text { 3. Inversión privada } \\
\text { en recursos humanos. }\end{array}$ & Ninguna, & $\begin{array}{l}\text { No hay prestamos para } \\
\text { educación o capacitación. }\end{array}$ & $\begin{array}{l}\text { Crear un mercado de } \\
\text { capital para inversión en } \\
\text { capital humano que } \\
\text { supere el problema de } \\
\text { falta de garantías. }\end{array}$ & $\begin{array}{l}\text { Uso de fondos } \\
\text { previsionales como } \\
\text { garantía de préstamos } \\
\text { educacionales y uso del } \\
\text { sistema previsional para } \\
\text { descontar el pago de esos } \\
\text { préstamos por planilla. }\end{array}$ \\
\hline $\begin{array}{l}\text { 4. Mayor } \\
\text { aproyechamiento } \\
\text { de las inversiones. }\end{array}$ & $\begin{array}{l}\text { Liberar las tasas } \\
\text { de interes. }\end{array}$ & $\begin{array}{l}\text { Segmentación: acceso } \\
\text { restringido al capita! de } \\
\text { largo plazo para las } \\
\text { empresas grandes. }\end{array}$ & $\begin{array}{l}\text { Crear instrumentos } \\
\text { financieros idóneos para } \\
\text { la pequeña y mediana } \\
\text { empresa. }\end{array}$ & $\begin{array}{l}\text { Fomento del uso del } \\
\text { leasing, los fondos de } \\
\text { garantía, los fondos de } \\
\text { capital de riesgo, la } \\
\text { segunda bolsa y las } \\
\text { tarjetas empresariales. }\end{array}$ \\
\hline $\begin{array}{l}\text { 5. Mejor utilización } \\
\text { del trabajo. }\end{array}$ & $\begin{array}{l}\text { Desregular el mercado } \\
\text { de trabajo. }\end{array}$ & $\begin{array}{l}\text { Relaciones laborales } \\
\text { conflictivas; baja } \\
\text { productividad; } \\
\text { inestabilidad en } \\
\text { el empleo. }\end{array}$ & $\begin{array}{l}\text { Modemizar las relaciones } \\
\text { laborales, fomentado el } \\
\text { pago de salarios por } \\
\text { resultados (participativos) } \\
\text { y no s6lo por tiempo. }\end{array}$ & $\begin{array}{l}\text { Autorización para } \\
\text { convertir parte de los } \\
\text { derechos de indemnización } \\
\text { por despido en salarios } \\
\text { participativos. } \\
\text { Cobro de menor } \\
\text { cotización previsional } \\
\text { sobre salarios } \\
\text { participativos. } \\
\text { Salarios participativos } \\
\text { para jóvenes que entran a } \\
\text { la empresa por primera vez. } \\
\text { Obligación de que } x \% \text { de } \\
\text { los aumentos salariales } \\
\text { sea participativo. }\end{array}$ \\
\hline 6. Ampliar mercado. & $\begin{array}{l}\text { Reducir los aranceles. } \\
\text { Mantener un tipo } \\
\text { de cambio alto y estable. }\end{array}$ & $\begin{array}{l}\text { Incentivo neutro; se } \\
\text { subaprovecha la } \\
\text { plataforma industrial } \\
\text { creada por la sustitucion } \\
\text { de ímportaciones. }\end{array}$ & $\begin{array}{l}\text { Imprimir un sesgo } \\
\text { transitorio pro exportador. }\end{array}$ & $\begin{array}{l}\text { Créditos, reintegros, } \\
\text { tributación especial para } \\
\text { exportaciones no } \\
\text { tradicionales y pioneras. } \\
\text { Fomento de la } \\
\text { internacionalización de } \\
\text { las empresas nacionales. }\end{array}$ \\
\hline $\begin{array}{l}\text { 7. Desarrollo } \\
\text { tecnológico. }\end{array}$ & Ignorarlo; es caja negra. & $\begin{array}{l}\text { Baja competitividad por } \\
\text { atraso tecnologico. }\end{array}$ & $\begin{array}{l}\text { Incorporar y difundir el } \\
\text { progreso técnico Lograr } \\
\text { una competitividad } \\
\text { sistémica. }\end{array}$ & $\begin{array}{l}\text { Organización de visitas a } \\
\text { plantas de mejores } \\
\text { prácticas en el exterior. } \\
\text { Fortalecimiento de la } \\
\text { infraestructura tecnologica } \\
\text { (especialmente informática } \\
\text { y las telecomunicaciones). } \\
\text { Articulacion de sistemas } \\
\text { productivos y tecnologicos. }\end{array}$ \\
\hline Rol del Estado. & Pasivo (desregular). & & $\begin{array}{l}\text { Activo } \\
\text { (promover). }\end{array}$ & \\
\hline
\end{tabular}


reducir el déficit fiscal, y por ende la inflación, equivale a una simple sustitución de un impuesto implícito por uno explícito, pero no eleva la carga tributaria neta efectiva. Por otra parte, la carga tributaria del sector privado en la región no es alta; de hecho, si se excluyen los impuestos pagados por las empresas estatales, sobre todo las que se dedican a la extracción de recursos naturales, dicha carga asciende en promedio al 16\% del PIB regional (con un máximo de 20 y $22 \%$ en México y Chile, respectivamente), siendo que en los países de la Organización de Cooperación y Desarrollo Económicos (OCDE) alcanza al 25\%. Por lo tanto, el margen para elevar la carga tributaria en la región parece ser amplio, sobre todo en los impuestos directos; éstos apenas alcanzan al 3\% del PIB, en tanto que en los países de la OCDE equivalen al $13 \%$ y en las economías asiáticas de industrialización reciente al $7 \%$.

Hay variadas opiniones sobre los métodos más adecuados para incrementar la recaudación. En lugar de elevar las tasas marginales de tributación, que suelen ser bastante altas, la CEPAL considera más provechoso aplicar, entre otras, las medidas siguientes: reducir la amplia gama de exenciones tributarias, que no sólo limitan la recaudación sino que además facilitan la evasión tributaria; ampliar la base tributaria (por ejemplo, estableciendo impuestos a las ganancias de capital, los dividendos, los intereses por dep6sitos a plazo, los arriendos, etc.) y reducir la enorme evasión tributaria actual.

Esto último no es un objetivo ilusorio, dado que hay países de la región que han logrado elevar la recaudación tributaria en cuatro años hasta en $4 \%$ del PIB por medio de campañas bien concebidas contra la evasión. Dichas campañas abarcan: i) medidas de simplificación tributaria para reducir el número de tasas, impuestos especiales y exenciones, que en muchos casos convierten a la legislación tributaria en una maraña incomprensible (en Chile, por ejemplo, antes de la reforma tributaria de 1975 las exenciones sumaban 164 páginas de texto); ji) drásticas sanciones a la evasión; iii) manejo computarizado de la información tributaria, con referencias cruzadas; iv) exámenes a los inspectores y despido de los menos preparados para que los restantes puedan recibir un sueldo más alto, y v) despido y castigo ejemplar de los funcionarios corruptos de mayor jerarquía del servicio de impuestos internos, especialmente si pertenecen al partido de gobierno, para que la campaña contra la corrupción funcionaria tenga credibilidad.

\section{b) Incremento del ahorro privado y de las inversiones}

Todos los expertos concuerdan también en que el incremento del ahorro privado y por consiguiente de las inversiones es fundamental para aumentar el número de empleos bien remunerados. En cambio, hay discrepancias en lo que se refiere a los instrumentos más adecuados para fomentar ese ahorro. Los analistas ortodoxos suelen proponer un aumento de las tasas de interés real para elevar el ahorro privado. La CEPAL está de acuerdo en que las tasas de interés real negativas reducen considerablemente el ahorro potencial. Sin embargo, tanto la práctica como la teoría ${ }^{3}$ indican que cuando en los países menos desarrollados las tasas de interés real alcanzan un nivel levemente superior al de las tasas internacionales, ${ }^{4}$ las alzas adicionales de las tasas de interés tienen escaso impacto sobre el ahorro.

Asimismo, por obvias consideraciones de equidad, la CEPAL tampoco es partidaria de la política ortodoxa clásica destinada a elevar el ahorro mediante la reducción de los salarios, transfiriendo recursos de los asalariados, cuya propensión a ahorrar es baja, a los dueños de capital, que se caracterizan por una alta propensión al ahorro. Por consiguiente, para elevar el ahorro privado la CEPAL propone la adopción de medidas de ahorro forzoso, ya sea por medio de una mayor tributación o de un mayor ahorro institucional. En ambos casos es necesaria la intervención del Estado. Por ejemplo, el alza de las tasas de cotización para la seguridad social y la postergación del pago de las pensiones hasta una edad más concordante con las mayores esperanzas de vida actuales elevarían el ahorro privado y permitirían hacer frente al déficit de $2 \%$ a $6 \%$ del PIB que afecta a los sistemas de seguridad social de la región.

\section{c) Asignación adecuada de las inversiones}

Tanto en términos de crecimiento como de equidad es importante no sólo elevar la inversión sino

\footnotetext{
3 El alza de las tasas de interes tiene un efecto de sustitución positivo, debido a que induce a postergar el consumo en lugar de consumir en el presente. Pero también tiene un efecto-ingreso negativo: de hecho, cuando las tasas de interés suben, el ingreso proveniente del ahorro aumenta, lo que reduce la necesidad de esforzarse por ahorrar. Este efecto negativo reduce e incluso puede anular el efecto de sustitución, lo que a su vez limita el incremento del ahorro ante el alza de las tasas de interes.

4 Las tasas de interés real de los países menos desarrollados tienden a ser más altas que las internacionales, debido a que sus economúas suelen estar sujetas a una mayor inestabilidad macroeconónica y política y, por lo tanto, el ahorro entraña un mayor riesgo.
} 
asegurar que ésta se asigne a los sectores más rentables. Según el criterio convencional, para aprovechar al máximo el escaso capital disponible se debe permitir la libre fluctuación de la tasa de interés. Al margen de las ventajas o desventajas que esta medida tenga, la CEPAL considera que la tasa de interés no puede ser el único instrumento de asignación de recursos, ya que los importantes vacíos, imperfecciones y segmentaciones de los mercados de capital de la región hacen necesario que el Estado tome medidas para corregir las graves y costosas distorsiones en la asignación de recursos derivadas de esas deficiencias.

En efecto, los mercados de capital están muy poco desarrollados, sobre todo en lo que se refiere a fondos de largo plazo, y el acceso al capital es muy segmentado, lo que va en desmedro de la mediana y pequeña empresa; por cierto, el acceso al capital a nivel internacional es aún más limitado. Por lo tanto, la movilidad del capital entre distintos agentes econ $6-$ micos, empresas, sectores y regiones se ve muy restringida; a esto contribuyen el alto costo de las transacciones (o la impresión de que éste es muy alto), la inadecuada práctica de exigir garantías en lugar de evaluar los proyectos como base para otorgar préstamos, y la preferencia de las empresas por invertir en firmas en las que tienen participación mayoritaria, en sectores similares o conexos, o en la misma región. Estas limitaciones obligan a la mayoría de las empresas a autofinanciarse en una proporción mucho mayor que la que sería necesaria en un mercado con perfecta movilidad de capital. Esta escasez artificial de capital tiene repercusiones particularmente graves en la región en términos de subempleo y desempleo, puesto que reduce la productividad de la mano de obra a un nivel mucho menor del que se lograría si el capital tuviera una perfecta movilidad o estuviera menos concentrado. 5

Para superar la escasez artificial de capital, la CEPAL propone, entre otras, las siguientes medidas enca-

\footnotetext{
5 En rigor, la concentración de la riqueza y la inmovilidad del capital no son los únicos factores determinantes de la adopción de técnicas que suponen un alto coeficiente de capital. También se debe tomar en consideración que la capacidad empresarial de quienes disponen de un gran volumen de capital no es absolutamente elástica, por lo que prefieren utilizar técnicas que suponen uso intensivo de capital y que permiten ahorrar mano de obra. De hecho, el empleo de tecnologías que impliquen uso intensivo de mano de obra y absorban todo el capital de una empresa también exige una estructura admministrativa extensa y compleja, que normalmente supera la capacidad empresarial y, adeinás, puede diluir el poder y control del empresario.
}

minadas a fortalecer y consolidar los mencados de capital: creación de fondos de inversión en capital de riesgo o en nuevas empresas; creación de un segundo mercado de valores para empresas familiares o cerradas, con exigencias de contabilidad y auditoría mayores que las actuales pero menores que las impuestas a las empresas cuyas acciones se transan en la Bolsa; conversión generalizada de activos financieros en valores (securitización); arriendo de equipos con opción de compra (leasing) y retrocesion en arriendo (leaseback) tanto de equipos de segunda mano como nuevos; factorización; exigencia de distribuir en dividendos el $100 \%$ de las utilidades a los accionistas (y posiblemente incluso los fondos de amortización); fomento de la reinversión de utilidades en la misma empresa o en otras por los accionistas o por las instituciones financieras intermediarias; y establecimiento de un impuesto sobre las tierras y las propiedades de acuerdo con su valor de mercado.

\section{d) Aumento de la inversión privada en capital humano}

Nadie duda de que las inversiones en capital humano aumentan significativamente la productividad total de los factores, sobre todo de la mano de obra, por lo que elevan su demanda. Para acrecentar tales inversiones se precisa un significativo esfuerzo, tanto del sector público como del sector privado. Sin embargo, debido a la falta de garantías "reales"para tales préstamos, no hay un mercado privado de préstamos para inversiones en capital humano. Es curioso que un hecho tan obvio e importante haya sido ignorado por la literatura especializada (con la notable excepción de Becker), ${ }^{6} \mathrm{y}$ por la política económica.

En efecto, pese a las elevadas tasas de rentabilidad privada y social de la educación general y de la capacitación y los estudios postsecundarios (típicamente superiores al $20 \%$ anual), casi no se otorgan préstamos privados para inversiones en estos campos. Si la familia o el mismo interesado no dispone de ahorros para financiar sus estudios, el trabajador queda a merced de su empresa, que tenderá a invertir śblo en la capacitación que eleve la productividad de la mano de obra dentro de ella, es decir, la capacitación específica. Esto explica que se invierta mucho menos de lo necesario en capacitación, a tal punto que un trabajador de la región recibe en promedio

6 Ya en su obra clásica Human Capital, Becker (1964) se refería a las consecuencias negativas de la virtual ausencia de un mercado de prestamos para inversiones en capital humano. Sin embargo la gran mayoría de los analistas no ha prestado atención al estudio de este mercado, tal vez por tratarse de algo inexistente. 
uno o dos meses de capacitación a lo largo de su vida laboral, que puede ser de 40650 años.

$\mathrm{La}$ falta de instituciones privadas que otorguen préstamos para realizar inversiones en capital humano se traduce en una inadecuada asignación de capital en la economía: se sobreinvierte en bienes de capital físico y se invierte menos de lo necesario en capital humano, con lo cual el producto nacional y la productividad total de los factores se reducen, incidiendo negativamente en la productividad y la demanda de mano de obra. Esta es una de las principales causas del subempleo y el desempleo en la región, y es un claro ejemplo de una falla de mercado que perjudica tanto la eficiencia como la equidad.

Para superar los problemas de falta de garantías y las dificultades de cobro, que virtualmente imposibilitan los préstamos privados para inversiones en capacitación y educación postsecundaria, la CEPAL ha propuesto aprovechar el hecho de que la mayoría de los trabajadores serán acreedores netos del gobierno al término de su vida laboral, debido al ahorro forzoso que significan sus contribuciones a la seguridad social. Concretamente, la CEPAL propone utilizar los derechos a pensión como garantía de tales préstamos, tanto los que se prevé que acumulará el deudor en el futuro como los efectivamente acumulados por su aval. Una vez concluidos los estudios, se descontaría automáticamente al deudor, por planilla, una cotización mayor a la normal -o en caso de mora a su aval- hasta que se cancele la deuda y los intereses. Esta combinación de garantía adecuada y seguridad de cobro estimularía al sector privado a conceder préstamos para inversiones en capital humano. ${ }^{7} \mathrm{Y}$ a la vez estimularía un mayor ahorro de los beneficiados y sus avales.

\section{e) Rigideces en el mercado del trabajo}

Los autores ortodoxos atribuyen el desempleo fundamentalmente a rigideces en el mercado de trabajo. Por lo tanto, hacen hincapié en las medidas que facilitan los despidos, limitan la sindicalizacion y las huelgas, desregulan la incorporación de trabajadores a determinadas actividades, y eliminan o reducen el salario mínimo. Es indudable que los monopolios sindicales y las barreras a la entrada pueden ser peligrosos; por ejemplo, en economías como las de la re-

\footnotetext{
7 En tal caso, se trata de que el ahorro forzoso del trabajador no sólo le dé beneficios en el futuro, cuando jubile, sino también en el presente. Esto será posible en la medida en que pueda utilizar como garantía las cotizaciones personales o de su aval, y siempre que la ley autorice las operaciones de este tipo, que actualmente están prohibidas.
}

gión, que tratan de insertarse en el mercado internacional, el control de las labores portuarias por parte de un gremio que limite el número de trabajadores podría tener un alto costo. Pero normalmente este tipo de problemas sólo afecta a una franja pequeña de la fuerza de trabajo.

El problema mayor del grueso de los trabajadores es la baja productividad de sus empleos. Y ello se debe en parte significativa a inflexibilidades derivadas de la práctica tradicional de pagar salarios fijos, que no vinculan el ingreso de los trabajadores al desempeño de la empresa. Esto limita notablemente el incremento potencial de la productividad y obliga a recurrir al despido como único método práctico para hacer frente a las recesiones.

Por consiguiente, la CEPAL aboga por un sistema de salarios flexibles (participativos), como el aplicado en Japón, la República de Corea y en la economía taiwanesa: allí una porción significativa del ingreso de los trabajadores en su conjunto se vincula al desempeño de la empresa, lo que eleva la productividad, promueve la cooperación y aminora los conflictos dentro de la empresa. Tanto o más importante, los salarios participativos favorecen un mayor empleo. En efecto, mientras las empresas que pagan salarios fijos suelen responder a una caída de la demanda de su producto con una reducción de sus niveles de producción y empleo, la empresa que paga salarios participativos tenderá a bajar sus precios para mantener las ventas y la producción y, por ende, el empleo, pues sabe que la baja de sus precios e ingresos se reflejará automáticamente en una menor masa salarial. Este hecho contribuye a explicar las buenas relaciones laborales, la alta productividad y el bajo desempleo existentes en el Japon.

Algunas de las medidas que se pueden adoptar para facilitar el uso de salarios participativos son las siguientes:

i) en vista de que habría menor desempleo, autorizar la conversión voluntaria de parte de los derechos de indemnización por despido contemplados en la legislación laboral de la mayoría de los países de la región en un determinado porcentaje del ingreso que variará en función del desempeño de la empresa;

ii) dado que los trabajadores jóvenes son los más perjudicados por la práctica actual de despedir al último en llegar, establecer un salario mínimo fijo inferior al actual para que, por ejemplo, un $20 \%$ o $25 \%$ de la remuneración del trabajador en un año normal provenga de un ingreso que varíe de acuerdo con el desempeño de la empresa; 
iii) dado que el uso general de salarios participativos genera una externalidad positiva para la economía, aproximando el producto y el empleo al nivel de pleno empleo, deducir para fines previsionales un porcentaje menor del componente de la remuneración del trabajador correspondiente a ingresos variables, $y$

iv) mấs importante aún, y también debido a la externalidad que suponen, estipular que los reajustes reales (superiores a la inflación esperada) correspondan exclusivamente a cierto porcentaje del ingreso del trabajador derivado del desempeño de la empresa, hasta que el porcentaje de salarios variables alcance el nivel deseado (por ejemplo, el $20 \%$ o el $25 \%$ de la remuneración del trabajador en un año normal).

\section{f) Inserción en mercados dinámicos de gran poder adquisitivo}

No se gana nada con producir más si no se puede vender. Para generar empleos productivos es preciso que los productos de la región lleguen a mercados dinámicos de alto poder adquisitivo. En efecto, mercados pequeños como los existentes en la región --salvo en Brasil y México-- limitan tanto la eficiencia como la equidad: lo primero porque no permiten economías de escala ni disfrutan de las ventajas de la especialización y lo segundo porque frenan la expansión del empleo. Por lo tanto, es imprescindible avanzar en la inserción internacional de la region.

Algunos autores estiman que así debería haber sido siempre. La CEPAL, en cambio, considera que la industrialización por medio de la sustitución de importaciones tuvo sentido como una primera etapa en la que las empresas tenían que aprender a producir. Por otra parte, la industrialización orientada hacia el exterior de hecho no era factible en los años treinta debido a la gran depresión, ni en los años cuarenta a causa de la guerra, ni en los años cincuenta por la reconstrucción europea. Sin embargo, hace ya tiempo que se hizo necesario pasar a la siguiente etapa, la de exportación de productos no tradicionales, en particular de manufacturas, para aprovechar mejor la plataforma industrial creada gracias a la estrategia de industrialización sustitutiva de las importaciones.

Por la razón que sea, actualmente no se cuestiona la importancia de la inserción internacional de América Latina y el Caribe, aunque hay discrepancias sobre cómo lograrla. Según la propuesta ortodoxa, para estimular las exportaciones hay que bajar los aranceles y mantener un tipo de cambio alto.

Ambas medidas son sin duda necesarias. Sin embargo, la CEPAL estima que no basta con utilizar instru- mentos neutrales para lograr una rápida y eficaz inserción en los mercados internacionales y así aprovechar mejor la estructura productiva generada en la etapa de sustitución de importaciones. Afirma que, por el contrario, el desafio que enfrenta la industria incipiente en la región ya no está en la producción, sino en la penetración de los mercados internacionales. Por ello, propone dar a la política económica un sesgo transitorio que favorezca tanto la apertura de nuevos mercados como las exportaciones no tradicionales (grafico 2), y aboga, a diferencia de la ortodoxia, por una promoción activa, pero selectiva y transitoria, de las exportaciones no tradicionales y de la apertura de nuevos mercados. Las primeras empresas en colocar exportaciones nuevas en los mercados externos, asf como las primeras en abrir nuevos mercados para exportaciones tradicionales, deben considerarse innovadoras schumpeterianas, y sus iniciativas e innovaciones merecen incentivos especiales transitorios, similares a las patentes que se otorgan a quienes elaboran nuevas tecnologías. Así se podrá aprovechar mejor la estructura industrial existente y se asegurará un mercado amplio y cada vez mayor, indispensable para generar un crecimiento sólido y sostenido del producto, del empleo y de los salarios reales. Por lo tanto, así como en el pasado el instrumento más adecuado para la industria incipiente era la sustitución de importaciones impulsada por un arancel protector, hoy los instrumentos más idóneos para las actividades realmente innovativas son los que fomentan las exportaciones y mercados no tradicionales por medio de subsidios transitorios, reintegros especiales y los créditos a tasas de interés internacionales.

GRAFICO 2

Estrategias alternativas para el desarrolio

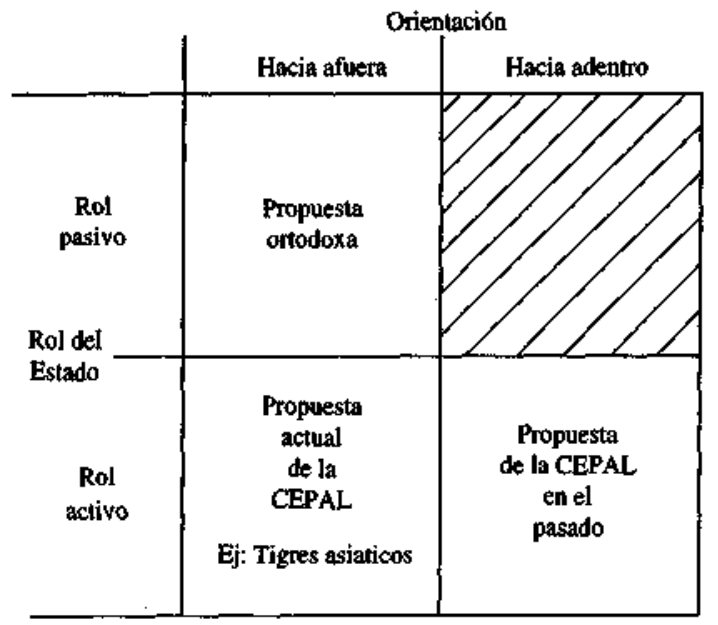




\section{g) Modemización tecnologica}

Hay una amplia diferencia de productividad entre la empresa típica de la región y la de los parses desarrollados, que compete a la empresa estrechar, seleccionando, adaptando y adoptando las "mejores prácticas" internacionales más idóneas para el país. Sin embargo, tal esfuerzo tiene un costo, cuyos beneficios recaen sólo parcialmente en la empresa que primero se moderniza. De ahí que habrá una subinversión en este esfuerzo, ya que cada empresa preferirá que otra absorba los costos de identificar, adoptar y desarrollar la tecnología más idónea para el país, mientras ella misma se dedica a imitarla rápidamente a mucho menor costo.

Por considerar que lo que sucede dentro de la empresa es de la exclusiva responsabilidad del empresario, y no del Estado, este problema microeconómico es normalmente ignorado por completo en el enfoque neoliberal. No así por el neoestructuralismo, que ve en la superación de este problema tal vez el mayor desafío para la modernización de las empresas y la eliminación de la diferencia de productividad; para ello, propone poner en marcha un programa masivo que acelere la difusion de las mejores tecnologías por medio del cofinanciamiento de visitas a fábricas de "mejor práctica" en el exterior, o sea una especie de "learning by visiting".

Tal como se hizo tan exitosamente en el programa de asistencia técnica para la reconstrucción de Europa, lo que se propone es organizar y cofinanciar ${ }^{8}$ visitas de inspección a seis y ocho plantas de mejor práctica en el exterior, ${ }^{9}$ por unas 15 a 20 personas (empresarios, ingenieros, técnicos, supervisores, operarios y sindicalistas) de cada uno de 50 subsectores (para un país típico de la región) ${ }^{10}$ por unas seis semanas. A su vuelta, cada grupo redacta- ría un informe sobre las mejores prácticas no sólo en cuanto a equipos y tecnologías, sino también en métodos de producción, organización del trabajo, relaciones industriales, control de calidad, comercialización, etc. Después, cada uno de los integrantes del grupo subsectorial difundiría los resultados de la visitas en cinco o diez empresas adicionales de su país.

En el caso europeo, con un costo muy bajo (aproximadamente 20 millones de d6́lares por país para enviar unas 20 personas por cada uno de 50 subsectores) se lograron aumentos de productividad del orden del 25 al $50 \%$ en cada empresa que participó, sin aumentos significativos en la inversión neta (Silberman y Weiss, 1992). De efectuarse un programa similar en la región, cabría esperar aumentos similares o aún mayores, ya que la disparidad entre la productividad total de los factores de los países desarrollados y de América Latina (aproximadamente de 2.5 a 1) es muy superior a la existente entre Estados Unidos y Europa a fines de los años cuarenta. El programa no sólo tiene una elevadísima relación costo/beneficio, sino que es masivo, ya que con el mismo multiplicador del Plan Marshall se alcanzaría a difundir la experiencia a entre 5000 y 10000 empresas. Esto permitiría que la región pudiera finalmente aprovechar la ventaja de su desarrollo tardío y saltarse etapas, moviéndose rápidamente hacia la frontera tecnológica mundial. ${ }^{11}$

Por cierto, un requisito para la rápida y eficaz adopción y adaptación de tecnología al medio local es que exista una mínima infraestructura científica y, particularmente, tecnológica, con cierta capacidad propia de investigación y desarrollo, estrechamente ligada al sistema productivo.

\footnotetext{
$8 \mathrm{El}$ cofinanciamiento podría implicar, por ejemplo, que las empresas mantengan los sueldos de su personal mientras este participa en las visitas y prepara el informe correspondiente, y que el aporte gubernamental cubra los costos de pasajes, viáticos y administración del programa (estimado en una cifra del orden de 20000 dólares por participante, o 20000000 de dólares por todo el programa para 20 personas en $\mathbf{5 0}$ ramas productivas).

9 En la época del Plan Marshall todas las fábricas de "mejor práctica" estaban en Estados Unidos. Hoy en día, por cierto, según sea el rubro, ellas se encuentran en Europa, Japón o Estados Unidos. De tal modo que se requerirá la colaboración ya no solo del gobiemo y los productores estadounidenses, sino de todos los países de la OCDE.

10 Obviamente el número de sectores y de fábricas de "mejor práctica" más relevantes variarán según el tamaño del país y su actual

grado de sofisticación tecnológica. No visitarán las mismas fábricas - aunque sean de mejor práctica- productores brasileños (de gran escala y sofisticación) y productores centroamericanos (de escala menor, con producción en nichos especializados e integrados, además de producción y comercialización mayores).

1 Además, esta propuesta hace que la productividad se vuelva un tema central y aglutinador y la fuente principal de mejoras solidas y duraderas en el nivel de vida de toda la población, requiriendo un esfuerzo nacional y no sólo de los empresarios o de algunos gremios. Asimismo, se evita el problema de elegir "ganadores" ya que el programa está abierto a todos los sectores que deseen participar o al menos a los primeros $\mathbf{5 0}$ que se organicen y presenten un programa para su sector cada affo y que estén dispuestos a participar en el cofinanciamiento del programa.
} 


\section{IV}

\section{Conclusiones}

En síntesis, el crecimiento con equidad no sólo es deseable desde el punto de vista ético, sino también posible desde el punto de vista técnico. Para superar la pobreza es preciso generar buenos empleos permanentes, de productividad alta y creciente; es decir, se necesita una política que apunte a modernizar la empresa y a elevar su productividad y la de su entomo. La CEPAL considera que, para lograr estos objetivos, no bastan las medidas de liberalización y desregula-

12 Las medidas mencionadas no constituyen un conjunto mínimo o máximo de acciones necesarias. Simplemente son un ejemplo de las que pueden adoptarse para superar los obstaculos existentes en los mercados, en caso de que éstos constituyan un problema crítico y siempre que el Estado tenga la capacidad institucional necesaria ción que constituyen la esencia de la propuesta tradicional, como si los mercados fuesen perfectos. Más bien aboga, de acuerdo a la tradición neoestructuralista, por instrumentos más activos que permitan superar los obstáculos críticos en los mercados claves (de capital físico y humano, trabajo, tecnología y divisas), estando el grado de activismo condicionado por la capacidad real del Estado de actuar, y de hacerlo en forma eficiente. ${ }^{12}$

para abordarlos sin dejar de desempeffar sus funciones fundamentales, entre otras la mantención de los equilibrios macroeconómi$\cos$, la realización de inversiones sociales y en infraestructura, y la provisión de un mínimo de seguridad social.

\section{Bibliografia}

Becker, Gary S. (1964): Human Capital, Nueva York, Columbia University Press.

CEPAl (Comisión Económica para América Latina y el Caribe) (1992): Equidad y transformacion productiva: un enfogue integrado (LC/G. 1701/Rev.1-P), Santiago de Chile. Publicación de las Naciones Unidas, $\mathrm{N}^{\circ}$ de venta S.92.II.G.5.

Fields, G. (1991): Poverty changes in the developing countries, documento presentado al Taller Internacional sobre Segui- miento de la Pobreza en las Agencias Internacionales, (Santiago de Chile, 11 al 13 de abril), Programa Regional del Empleo para América Latina y el Caribe (PREALC)/Fondo de las Naciones Unidas para la Infancia (UNICEF), mimeo.

Silberman, James y Charles Weiss Jr. (1992): Restructuring for productivity: The technical assistance program of the Marshall Plan as a precedent for the former Soviet Union, trabajo preparado para el Banco Mundial. 